\title{
Direct Gene Delivery of Human Tissue Kallikrein Reduces Blood Pressure in Spontaneously Hypertensive Rats
}

\author{
Cindy Wang, Lee Chao, and Julie Chao \\ Department of Biochemistry and Molecular Biology, Medical University of South Carolina, Charleston, South Carolina 29425-2211
}

\begin{abstract}
Hypertension is a multigene and multifactorial disorder affecting $\sim 25 \%$ of the population. To demonstrate potential therapeutic effects of human tissue kallikrein in hypertension, spontaneously hypertensive rats were subjected to somatic gene therapy. Two human tissue kallikrein DNA constructs, one under the promoter control of the metallothionein metal response element and the other under the control of the Rous sarcoma virus $3^{\prime}$-LTR, were generated. We delivered naked DNA constructs into spontaneously hypertensive rats via intravenous injection. The expression of human tissue kallikrein in rats was identified in the heart, lung, and kidney by reverse transcription polymerase chain reaction followed by Southern blot analysis and an ELISA specific for human tissue kallikrein. A single injection of both human kallikrein plasmid DNA constructs caused a sustained reduction of blood pressure which began 1 wk after injection and continued for 6 wk. A maximal effect of blood pressure reduction of $46 \mathrm{mmHg}$ in rats was observed 2-3 wk after injection with kallikrein DNA as compared to rats with vector DNA $(n=6, P<0.05)$. The hypotensive effect caused by somatic gene delivery of human tissue kallikrein in hypertensive rats is reversed by subcutaneous injection of aprotinin, a potent tissue kallikrein inhibitor. No antibodies to either human tissue kallikrein or kallikrein DNA were detected in rat sera after injection of the human kallikrein gene. These results show that direct gene delivery of human tissue kallikrein causes a sustained reduction in systolic blood pressure in genetically hypertensive rats and indicate that the feasibility of kallikrein gene therapy for treating human hypertension should be studied. (J. Clin. Invest. 1995. 95:1710-1716.) Key words: somatic gene therapy • kallikrein • hypertension • aprotinin • spontaneously hypertensive rat
\end{abstract}

\section{Introduction}

Tissue kallikreins (E.C. 3.4.21.35) belong to a subgroup of serine proteinases which are involved in the posttranslational processing of peptide precursors to their bioactive forms. One of the main biological functions of tissue kallikrein is to process

Address correspondence to Julie Chao, Department of Biochemistry \& Molecular Biology, Medical University of South Carolina, Charleston, SC 29425-2211. Phone: 803-792-4321; FAX: 803-792-4322.

Received for publication 5 August 1994 and in revised form 21 October 1994.

J. Clin. Invest.

(C) The American Society for Clinical Investigation, Inc.

0021-9738/95/04/1710/07 \$2.00

Volume 95, April 1995, 1710-1716 kininogen substrates and release vasoactive kinin peptides (1, 2 ). Kinins have a broad spectrum of biological effects including vasodilation, smooth muscle contraction and relaxation, pain, inflammation, increase in ion and glucose transport, and reduction of blood pressure. The fact that kinin has a low concentration in plasma and a short half-life in the circulation suggests that kinin acts as a local hormone.

The tissue kallikrein-kinin system has been implicated in the pathogenesis of hypertension $(3,4)$. Essential hypertension appears to be a polygenic disease and several genes are likely involved in the genetic determination of blood pressure. The observation that urinary excretion of tissue kallikrein was significantly reduced in hypertensive individuals was reported in 1934 and confirmed more than three decades later $(5,6)$. Epidemiological studies showed that urinary kallikrein levels are inversely correlated with blood pressure in infants, children, and parents $(7,8)$. A study involving Utah pedigrees indicates that a dominant allele expressed as high urinary kallikrein excretion may be associated with a decreased risk of essential hypertension (9). Reduced urinary kallikrein excretion has also been described in a number of genetically hypertensive rats (1013). In addition, rat tissue kallikrein has been linked with blood pressure regulation by restriction fragment length polymorphism and cosegregation studies in genetically hypertensive rats $(14,15)$. These findings suggest that low renal kallikrein levels may contribute to hypertension and high urinary kallikrein could have a protective effect against hypertension. Clinical studies have shown that the blood pressure of hypertensive patients can be temporarily lowered by oral administration of pig pancreatic kallikrein $(16,17)$. However, to achieve this hypotensive effect, a large quantity and repeated administration of purified tissue kallikrein are required.

To establish the role of the kallikrein-kinin system in blood pressure control, we developed transgenic mouse lines that express the human tissue kallikrein gene under the control of the metal response element (MRE) ${ }^{1}$ promoter of the metallothionein gene (18). We found that transgenic mice overexpressing human tissue kallikrein, which is secreted into the circulation, have a sustained reduction in blood pressure. Administration of aprotinin, a tissue kallikrein inhibitor, to these transgenic mice restored blood pressure to normal. Since these results suggested a direct link between tissue kallikrein and blood pressure regulation, we decided to apply kallikrein gene therapy to reduce blood pressure in hypertensive rat models. In this study, we

1. Abbreviations used in this paper: low $M_{\mathrm{r}}$, low molecular weight; MRE, metal response element; MRE-pHK, plasmid construct in which the expression of human tissue kallikrein is driven by the metal response element of the mouse metallothionein (mMT-1) gene; RSV, Rous sarcoma virus; RSV-cHK, plasmid construct in which the expression of human tissue kallikrein is driven by $3^{\prime}$-LTR of Rous sarcoma virus; RT-PCR, reverse transcription PCR; SHR, spontaneously hypertensive rat. 
found that direct delivery of the human tissue kallikrein gene into spontaneously hypertensive rats (SHR) by intravenous injection induced a sustained reduction of blood pressure for at least $6 \mathrm{wk}$. These findings suggest the feasibility of introducing DNA encoding therapeutic kallikrein for treating human hypertensive diseases.

\section{Methods}

Materials. Aprotinin (6,700 kallikrein inhibitor units/mg), L-1-tosylamide-2-phenylethyl chloromethyl ketone (TPCK)-treated trypsin, and soybean trypsin inhibitor were purchased from Sigma Chemical Co. (St. Louis, MO). The eukaryotic expression vector pREP8 was purchased from Invitrogen (San Diego, CA). Male SHR weighing 200$220 \mathrm{~g}$ (Harlan Sprague Dawley, Inc., Indianapolis, IN) were used. The rats were housed at a constant room temperature with a 12-h light/dark cycle and had free access to tap water and rat chow.

Rous sarcoma virus-( $R S V$-cHK) plasmid DNA preparation. Human tissue kallikrein cDNA encoding the entire coding sequence (nucleotides 32-866) was amplified from the RNA of human colonic carcinoma T84 cells by reverse transcription-polymerase chain reaction (RT-PCR). The sense primer used was 5'-CCACCATGGGGTTCCTGGTT-3' from 32 to 51 of human tissue kallikrein cDNA and the antisense primer was 5'-CACGGATCCACATTTGATTTT-3' from 874 to 854 of the 3'untranslated region (19). The amplified product was cloned into PCR $^{\mathrm{TM}}$ II vector (Invitrogen) according to the manufacturer's instructions. To construct plasmid RSV-cHK, the human tissue kallikrein insert (nucleotides 32-866) was released from PCR ${ }^{\mathrm{TM}} \mathrm{II}$ vector by XhoI and BamHI digestion and cloned into the plasmid PREP8 at XhoI and BamHI sites. The expression of human tissue kallikrein cDNA encoding the entire coding sequence (19) was under the transcriptional control of the Rous sarcoma virus 3' long terminal repeat promoter in plasmid RSVcHK. The human tissue kallikrein cDNA incorporated two minor changes from the published sequence ( $T$ to $C$ at nucleotide $32 ; T$ to $G$ at nucleotide 40 ), and included a Kozak translation initiation sequence (CCACCATGG) immediately $5^{\prime}$ to the translation initiation codon (20). The plasmid metal response element (MRE-pHK), the human tissue kallikrein gene under the control of the MRE of the mouse metallothionein gene (21), was constructed as previously described (18).

Transient transfection of Hep G2 cells. Human hepatoma Hep G2 cells at $80 \%$ confluency were transfected with $15 \mu \mathrm{g}$ of plasmid DNA RSV-cHK and MRE-pHK by the calcium phosphate precipitation method (22). $16 \mathrm{~h}$ after transfection, Hep G2 cells were shocked with $1.5 \mathrm{ml}$ of $15 \%$ glycerol in $1 \times \mathrm{HBS}$ buffer $(140 \mathrm{mM} \mathrm{NaCl}, 5 \mathrm{mM} \mathrm{KCl}$, $0.75 \mathrm{mM} \mathrm{Na}_{2} \mathrm{HPO}_{4} \cdot 2 \mathrm{H}_{2} \mathrm{O}, 6 \mathrm{mM}$ dextrose, $25 \mathrm{mM}$ Hepes, $\mathrm{pH} 7.05$ ) for $1 \mathrm{~min} .50 \mathrm{~h}$ after glycerol shock, Hep G2 cells and DME medium containing $10 \%$ FCS were collected. Hep G2 cells were lysed by three cycles of freeze-thawing in $100 \mu \mathrm{l}$ of PBS. Prekallikrein was activated by incubation with $1 \mu \mathrm{g}$ of TPCK-treated trypsin for $6 \mathrm{~min}$ at $37^{\circ} \mathrm{C}$ and the activation was stopped by adding $5 \mu \mathrm{g}$ of soybean trypsin inhibitor (23). The immunoreactive human tissue kallikrein was assayed by a direct RIA specific for human tissue kallikrein as previously described (24).

Enzymatic assays toward low molecular weight (low $M_{r}$ ) kininogen substrates. Rat low $M_{\mathrm{r}}$ kininogen was isolated according to the method of Johnson et al. (25). Human and rat tissue kallikreins were purified as previously described (24). Kinin-releasing activities of human and rat tissue kallikrein were measured by incubating the purified enzyme (50 ng) with rat low $M_{\mathrm{r}}$ kininogen, bovine low $M_{\mathrm{r}}$ kininogen, canine low $M_{\mathrm{r}}$ kininogen, or human low $M_{\mathrm{r}}$ kininogen $(3 \mu \mathrm{g})$ in $0.1 \mathrm{M}$ sodium phosphate (pH 8.5) in a total vol of $500 \mu \mathrm{l}$ at $37^{\circ} \mathrm{C}$ for $30 \mathrm{~min}$. The reactions were stopped by boiling for $20 \mathrm{~min}$. Released kinin was assayed by a kinin RIA (26).

DNA delivery. The plasmid DNA of pREP8 vector, RSV-cHK, and MRE-pHK were purified with a plasmid purification kit (QIAGEN, Chatsworth, CA) according to the manufacturer's instructions. 18 SHR were randomly divided into three groups with six animals in each. Three plasmid DNA constructs, pREP8, RSV-cHK, and MRE-pHK, were diluted to $500 \mu \mathrm{g} / \mathrm{ml}$ in PBS containing $5 \%$ glucose and were injected into the tail vein of SHR at a dose of $500 \mu \mathrm{g} /$ rat.

Blood pressure measurement. Systolic blood pressure of SHR was measured with a programmed electro-sphygmomanometer (PE-300; Narco Bio-Systems, Inc., Austin, TX) using the tail-cuff method (18). Unanesthetized rats were placed in a plastic holder mounted on a thermostatically controlled warm plate that was maintained at $37^{\circ} \mathrm{C}$ during measurement. An average of six readings were taken for each animal.

Aprotinin administration. Six SHR injected with MRE-pHK plasmid DNA were randomly divided into two groups 6 wk after plasmid DNA delivery. In the control group, three SHR were subcutaneously injected with $0.5 \mathrm{ml}$ of PBS and in the aprotinin group, three SHR were subcutaneously injected with $5 \mathrm{mg}$ of aprotinin in $0.5 \mathrm{ml}$ of PBS. The effect of aprotinin on the blood pressure of SHR injected with MRE-pHK plasmid DNA was evaluated at 1 and $3 \mathrm{~d}$ after aprotinin administration.

ELISA specific for human tissue kallikrein. Rats treated with kallikrein DNA or vector DNA were anesthetized with pentobarbital and perfused with saline $(0.85 \% \mathrm{NaCl})$. Tissues were immersed in PBS (pH 7.0), and homogenized immediately with a Polytron (Brinkman Instruments, Westbury, NY). The homogenate was centrifuged at 600 $g$ for $10 \mathrm{~min}$. The supernatant was incubated in $0.5 \%$ sodium deoxycholate and then centrifuged at $10,000 \mathrm{~g}$ for $30 \mathrm{~min}$. Total protein was determined by Lowry's method (27). The level of human tissue kallikrein in each tissue extract was determined by ELISA specific for human tissue kallikrein using methods similar to previously described procedures (28). Anti-human tissue kallikrein IgG was coupled to biotin (29). Microtiter plates (96 well) were coated with antikallikrein IgG $(2 \mu \mathrm{g} / \mathrm{ml}, 100 \mu \mathrm{l} /$ well $)$ overnight at $4^{\circ} \mathrm{C}$. Purified kallikrein standard $(0.04-2.5 \mathrm{ng})$ and rat tissue extracts were added to individual wells in a total vol of $100 \mu \mathrm{l}$ of PBS containing $0.05 \%$ Tween-20 and $0.5 \%$ gelatin (dilution buffer). Biotin-labeled anti-human tissue kallikrein IgG was added in each well at a concentration of $1 \mu \mathrm{g} / \mathrm{ml}$ in a total of $100 \mu \mathrm{l}$. Peroxidase-avidin $(1 \mu \mathrm{g} / \mathrm{ml}$ in a total of $100 \mu \mathrm{l})$ was added and incubated at $37^{\circ} \mathrm{C}$ for $60 \mathrm{~min}$. The color reaction was performed by adding $100 \mu \mathrm{l} /$ well of freshly prepared substrate solution [0.03\% $2,2^{\prime}$ azino-bis (3-ethylbenzthiazoline-6-sulfonic acid) and $0.03 \% \mathrm{H}_{2} \mathrm{O}_{2}$ in 0.1 $\mathrm{M}$ citrate buffer, $\mathrm{pH} \mathrm{4.3]} \mathrm{and} \mathrm{incubating} \mathrm{at} \mathrm{room} \mathrm{temperature} \mathrm{for} 30$ $\mathrm{min}$. The plates were read at $414 \mathrm{~nm}$ with a Titertek plate reader (Elfab Oy, Finland).

Assays for serum antibodies in rats. Immunological responses were monitored by measuring production of antibodies against human tissue kallikrein or kallikrein plasmid DNA (MRE-pHK) in the sera of experimental rats. Serum antibodies binding to human tissue kallikrein protein or kallikrein DNA were measured by ELISA (28). Microtiter ELISA plates were coated with either purified human tissue kallikrein at $5 \mu \mathrm{g} /$ $\mathrm{ml}$ in PBS at $4^{\circ} \mathrm{C}$ or with purified kallikrein DNA construct at $5 \mu \mathrm{g} / \mathrm{ml}$ in SSC ( $150 \mathrm{mM}$ sodium chloride, $15 \mathrm{mM}$ sodium citrate, $\mathrm{pH} 7.0$ ) at $37^{\circ} \mathrm{C}$ overnight $(30)$. Serially diluted rat sera in PBS containing $0.05 \%$ Tween 20 were added to the plates. After incubation for $\mathbf{4 5} \mathrm{min}$ at room temperature, plates were washed and peroxidase-conjugated goat antirat IgG was added. Substrate solution was added and the plates were read at $414 \mathrm{~nm}$ on a Titertek plate reader.

RT-PCR Southern blot analysis of human tissue kallikrein mRNA. Total RNA was extracted from fresh rat tissues or human colonic carcinoma $\mathrm{T} 84$ cells by guanidine isothiocyanate- $\mathrm{CsCl}$ gradient centrifugation (31). The reaction mixture for RT contained $1 \mu \mathrm{g}$ of total RNA from human colonic carcinoma T84 cell or $4 \mu \mathrm{g}$ of total RNA from SHR, 20 pmol of the 3' primer (5'-GCCACAAGGGACGTAGC-3' located on the fifth exon of the human tissue kallikrein gene), $20 \mathrm{nmol}$ of dNTP, $0.2 \mu \mathrm{mol}$ of DTT, $4 \mu \mathrm{l}$ of $5 \times$ reverse transcription buffer ( $250 \mathrm{mM}$ Tris- $\mathrm{HCl}, \mathrm{pH} \mathrm{8.3,375} \mathrm{mM} \mathrm{KCl}, 15 \mathrm{mM} \mathrm{MgCl}_{2}$ ) and $200 \mathrm{U}$ of Maloney murine leukemia virus reverse transcriptase (BRL, Gaitherburg, MD), in a total volume of $20 \mu \mathrm{l}$. The reverse transcription (RT) reaction mixture was incubated at $37^{\circ} \mathrm{C}$ for $1 \mathrm{~h}$ to synthesize the first strand of cDNA. 20 pmol of $5^{\prime}$ primer (5'-CATTTCAGCACTTTCCA$3^{\prime}$ located on the second exon of the human tissue kallikrein gene), 5 $\mu \mathrm{l}$ of $10 \times$ PCR buffer, and $0.5 \mathrm{U}$ of Taq DNA polymerase were added 

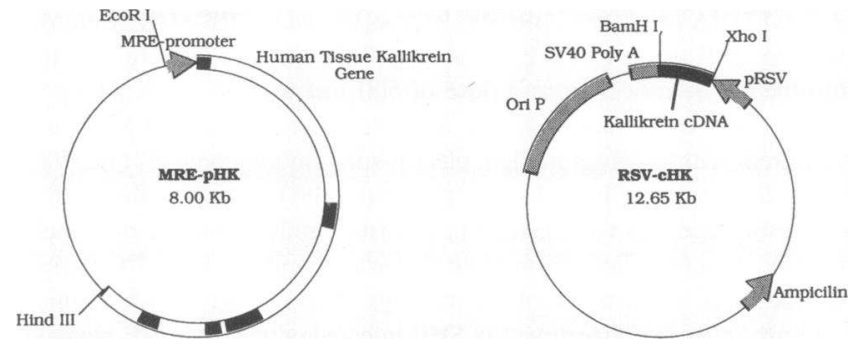

Figure 1. Human tissue kallikrein plasmid DNA constructs. (Left) MRE-pHK, human tissue kallikrein gene was under the control of an MRE promoter of the mouse metallothionein gene (18). The shaded arrow represents the MRE promoter and the filled and open blocks (representing the five exons and the four introns) show the promoterless human tissue kallikrein gene sequence $(5.6 \mathrm{~kb})$ containing the entire coding sequence and 300 bp of the 3 ' flanking sequence. (Right) RSVcHK, human tissue kallikrein cDNA construct under the control of RSV $3^{\prime}$ long terminal repeat promoter as indicated by the shaded arrow (pRSV). SV40 Poly A represents the polyadenylation signal. The solid block represents a full-length human tissue kallikrein cDNA ( 834 bp). Human tissue kallikrein cDNA was cloned into the pREP8 at BamHI and XhoI restriction sites, as indicated. The thin line and shaded blocks represent the vector sequence.

to the RT mixture to a total vol of $50 \mu \mathrm{l}$ followed by 35 cycles of hotstart PCR $\left(94^{\circ} \mathrm{C}, 1 \mathrm{~min} ; 55^{\circ} \mathrm{C}, 1 \mathrm{~min} ; 72^{\circ} \mathrm{C}, 1 \mathrm{~min}\right)$ with Ampliwax (Perkin-Elmer Cetus Instruments, Norwalk, CT) in a thermal cycler. 30 $\mu \mathrm{l}$ of the RT-PCR products was subjected to a Southern blot analysis. A specific oligonucleotide ( $5^{\prime}$-ACGACCTTCACAGCGTC- 3 ' located on the third exon of the human tissue kallikrein gene) was used as a probe for hybridization at $42^{\circ} \mathrm{C}$. The membrane was washed in $6 \times$ SSC twice at room temperature and exposed to X-Omat film at $-80^{\circ} \mathrm{C}$ (Eastman Kodak Co., Rochester, NY).

Statistical analysis. Data were analyzed using standard statistical methods. Representative data from four or more experiments are depicted. To assess blood pressure changes after gene delivery, repeated measures for ANOVA were performed to compare the differences among control, MRE-pHK, and RSV-cHK groups. One factor ANOVA followed by Fisher's probability of least significant difference was used to evaluate the effect of human tissue kallikrein gene delivery in MREpHK and RSV-cHK groups. In addition, we used an unpaired Student's $t$ test to assess the difference in systolic blood pressure of SHR receiving MRE-pHK gene construct between aprotinin-treated and control groups. Group data are expressed as mean \pm SE. Values were considered significantly different at a value of $P<0.05$.

\section{Results}

Expression of human tissue kallikrein gene in Hep G2 cells. Expression of human tissue kallikrein was analyzed in Hep G2 cells transiently transfected with two human tissue kallikrein plasmid DNA constructs, MRE-pHK or RSV-cHK (Fig. 1). No endogenous human tissue kallikrein can be detected in Hep G2 cell extract or culture medium by human tissue kallikrein specific RIA. About $99 \%$ of immunoreactive human tissue kallikrein synthesized in Hep G2 cells was secreted into the cultured medium and only $1 \%$ of the immunoreactive material was stored in the cells. In cultured medium, the level of human tissue kallikrein in Hep G2 cells transfected with RSV-cHK plasmid DNA $(22.3 \mathrm{ng} / \mathrm{ml})$ was twice that of cells transfected with MRE-pHK plasmid DNA (12.4 ng/ml). Human tissue kallikrein was secreted as both active enzyme and latent kallikrein. Trypsin activation increased immunoreactive kallikrein levels
Table I. Kinin-releasing Activities of Human and Rat Tissue Kallikreins

\begin{tabular}{lrr}
\hline & \multicolumn{2}{c}{ Tissue kallikrein* } \\
\cline { 2 - 3 } \multicolumn{1}{c}{ Substrate } & Human & Rat \\
\hline Rat low $M_{\mathrm{r}}$ kininogen & 20 & 138 \\
Human low $M_{\mathrm{r}}$ kininogen & 159 & 223 \\
Bovine low $M_{\mathrm{r}}$ kininogen & 117 & 45 \\
Canine low $M_{\mathrm{r}}$ kininogen & 186 & 152 \\
\hline
\end{tabular}

* Specific activity is expressed as micrograms of kinin released per milligram of enzyme in $30 \mathrm{~min}$ at $37^{\circ} \mathrm{C}$. Values represent two assays in duplicate $(n=4)$.

by 47 and $23 \%$ in MRE-pHK ( $18.2 \mathrm{ng} / \mathrm{ml})$ and RSV-cHK (27.4 $\mathrm{ng} / \mathrm{ml}$ ) -transfected Hep G2 cultured media, respectively. For the MRE-pHK construct, $68 \%$ of human tissue kallikrein produced in Hep G2 cells is the active form and $32 \%$ is the proenzyme form. For the RSV-cHK construct, $81 \%$ of human tissue kallikrein produced in Hep G2 cells is the active form and 19\% is the proenzyme form.

Kininogenase activity of human tissue kallikrein. Kinin-releasing activities of purified human and rat tissue kallikreins on kininogen substrates from various species are shown in Table I. Rat tissue kallikrein cleaves rat low $M_{\mathrm{r}}$ kininogen releasing $138 \mu \mathrm{g} \mathrm{kinin} / \mathrm{mg}$ kallikrein per $30 \mathrm{~min}$ at $37^{\circ} \mathrm{C}$. Human tissue kallikrein cleaves rat low $M_{\mathrm{r}}$ kininogen releasing $20 \mu \mathrm{g}$ kinin/ mg enzyme per $30 \mathrm{~min}$ at $37^{\circ} \mathrm{C}$. Although human tissue kallikrein shows high specific activities toward human, bovine, and canine low $M_{\mathrm{r}}$ kininogens, it has $\sim 15 \%$ of the kinin-releasing activity of rat tissue kallikrein on rat low $M_{\mathrm{r}}$ kininogen substrate. Rat tissue kallikrein shows high specific activity toward rat, human, canine, and bovine low $M_{\mathrm{r}}$ kininogens. Neither rat tissue kallikrein nor human tissue kallikrein displays significant activities toward rat T-kininogen (data not shown).

Detection of human tissue kallikrein $\mathrm{mRNA}$ and protein in SHR after gene delivery. Expression levels of human tissue kallikrein in SHR were analyzed after intravenous injection of the kallikrein DNA by an ELISA specific for human kallikrein. The results show that human tissue kallikrein gene expression was detected in the kidney, lung, and heart at $21 \mathrm{~d}$ after intravenous injection. Low level human kallikrein expression in the aorta was also detected (data not shown). Linear displacement curves for immunoreactive kallikrein in the heart, lung, and kidney of SHR were parallel with the standard curve of human tissue kallikrein, indicating their immunological identity (Fig. 2). Immunoreactive human tissue kallikrein was not detected by ELISA in the heart, lung, or kidney of control rats that received vector DNA alone. The results indicate that the rabbit anti-human tissue kallikrein antibody is specific for human tissue kallikrein and has no cross-reaction with rat tissue kallikrein gene family members.

The MRE-pHK plasmid DNA was injected intravenously into five SHR with a dose of $500 \mu \mathrm{g}$ per rat, respectively. SHR given the same amounts of vector DNA were used as controls. The MRE-pHK plasmid DNA-injected rats were killed $21 \mathrm{~d}$ after injection. Total RNAs prepared from heart, lung, and kidney of SHR were analyzed for the human tissue kallikrein transcript by using specific oligonucleotide probes for human tissue kallikrein. RT-PCR Southern blot analysis showed that the hu- 


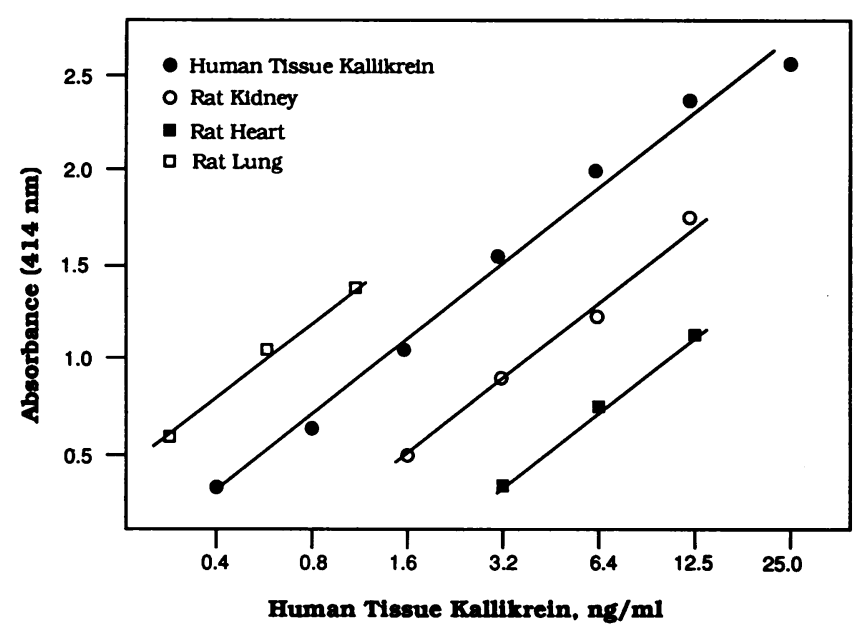

Figure 2. ELISA of human tissue kallikrein in tissues of SHR receiving intravenous injection of MRE-pHK plasmid DNA. Human tissue kallikrein standard curve ranging from 0.04 to $2.5 \mathrm{ng}$ is shown by the filled circles $(\bullet)$, and serial dilutions of rat tissue extracts are shown as follows: heart ( $\square)$, kidney $(O)$, and lung ( $\square$ ).

man kallikrein gene was expressed in kidney, lung, and heart (Fig. 3). The RT-PCR products from control rats did not hybridize to the human tissue kallikrein probe. These results indicate that RT-PCR Southern blot analysis is specific for human tissue

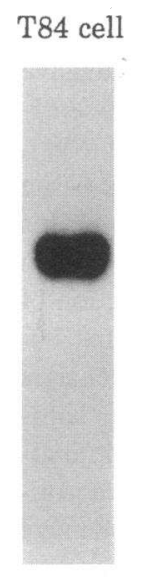

pHK-MRE

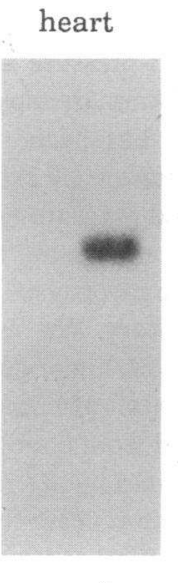

$+$

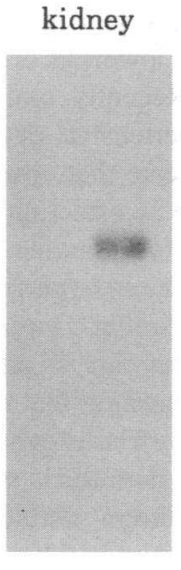

$-\quad+$ lung

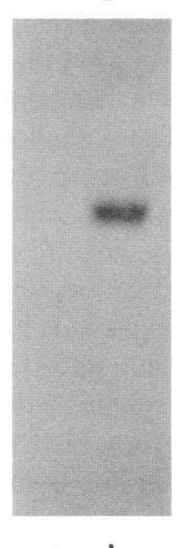

$+$
Figure 3. Expression of human tissue kallikrein mRNA in SHR after human tissue kallikrein gene delivery. $1 \mu \mathrm{g}$ of cell RNA or $4 \mu \mathrm{g}$ of tissue RNA was used for each RT-PCR Southern blot analysis. Southern blot analysis of RT-PCR products was carried out in $5 \times$ sodium chloride sodium phosphate EDTA ( $750 \mathrm{mM}$ sodium chloride, $50 \mathrm{mM}$ sodium phosphate, 5mM EDTA, pH7.4), 0.5\% SDS, $5 \times$ Denhardt's solution, $100 \mu \mathrm{g} / \mathrm{ml}$ single stranded DNA at $42^{\circ} \mathrm{C}$ for $16 \mathrm{~h}$ with ${ }^{32} \mathrm{P}$-end-labeled oligonucleotide probe. The blot was washed to a final stringency of 6 $\times$ SSC at room temperature before autoradiography at $-80^{\circ} \mathrm{C}$ for $24 \mathrm{~h}$ with an intensifying screen. T84 cell represents human colonic carcinoma T84 cell RNA as a positive control. RNA from heart, kidney, and lung of SHR are indicated in the figure. MRE-pHK " -" indicates RNA extracted from SHR which received vector DNA; MRE-pHK "+" indicates RNA extracted from SHR which received intravenous injection of MRE-pHK kallikrein DNA construct. The rats were killed at $21 \mathrm{~d}$ after gene delivery.

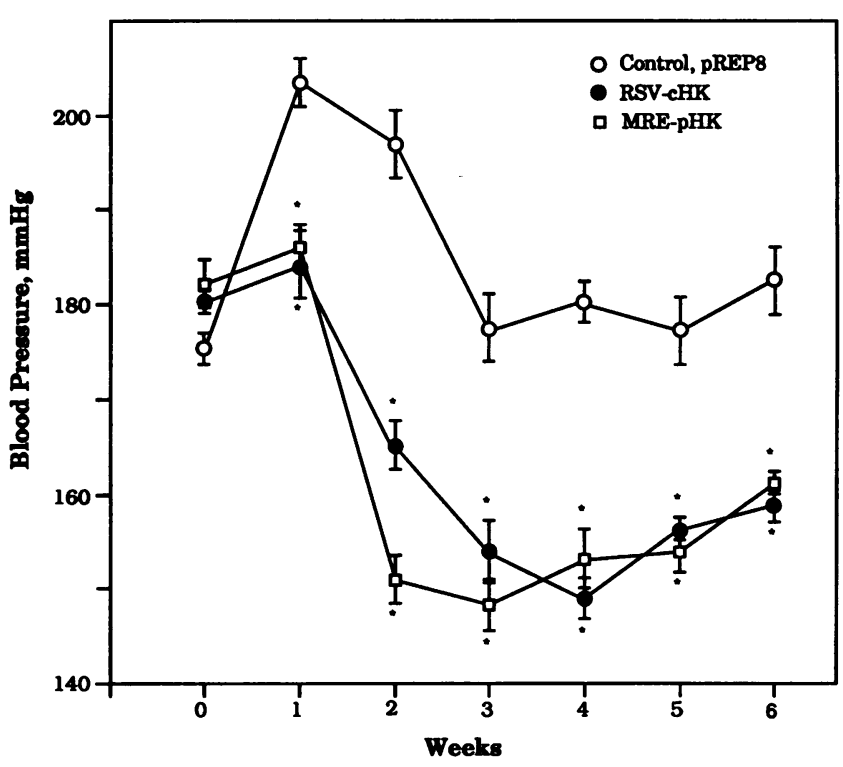

Figure 4. Systolic blood pressure of spontaneously hypertensive rats after intravenous injection of control vector DNA ( $p R E P 8)$, human tissue kallikrein cDNA under the control of RSV 3'-long terminal repeat $(R S V-c H K)$, and human tissue kallikrein gene under the control of MRE promoter $(M R E-p H K)$. Blood pressure values are expressed as mean $\pm S E(n=6)$. Bars represent standard deviation. ${ }^{*} P<0.05$ between MRE-pHK or RSV-cHK group vs pREP8 control group $(n=6)$.

kallikrein and that endogenous rat tissue kallikrein family members do not interfere with the assay.

Intravenous injection of human tissue kallikrein DNA does not cause immunoresponse. Direct delivery of the human tissue kallikrein gene into SHR induces expression of exogenous human tissue kallikrein. To examine the possibility of antibody production against human kallikrein protein or its DNA in the rat, we used ELISA to measure antibody levels in the sera of the rats injected with kallikrein DNA construct and control rats. When using serial dilutions of rat sera from $1: 2$ to $1: 1,000$, we did not detect any antibodies against either human kallikrein protein or kallikrein DNA at 1-6 wk after injection.

Hypotensive effect of gene delivery of human tissue kallikrein to SHR. The effect of administering two human tissue kallikrein DNA constructs, RSV-cHK and MRE-pHK on the blood pressure of SHR was determined 1-6 wk after intravenous injection. The plasmid vector pREP8 DNA was injected intravenously as a control. The results show that the kallikrein constructs produced a significant reduction in systolic blood pressure (Fig. 4). The basal blood pressure was 170-190 $\mathrm{mmHg}$ in all experimental groups before gene delivery. Systolic blood pressure in SHR injected with the vector pREP8 plasmid DNA increased 28 and $22 \mathrm{mmHg}$ at 1 and 2 wk after injection, respectively. Increases in systolic blood pressure of $\sim 20$ $\mathrm{mmHg}$ at 1 and 2 wk after intravenous injection were occasionally observed. The systolic blood pressures of SHR injected with RSV-cHK ( $184 \pm 7 \mathrm{mmHg}, n=6)$ and MRE-pHK (186 \pm 4 $\mathrm{mmHg}, n=6$ ) were significantly decreased ( $P<0.05$ ), compared with SHR injected with pREP8 vector DNA $(203 \pm 5$ $\mathrm{mmHg}, n=6$ ) $1 \mathrm{wk}$ after injection. The reduction of systolic blood pressure was sustained for 6 wk. The differences in systolic blood pressure of SHR administered with vector DNA 


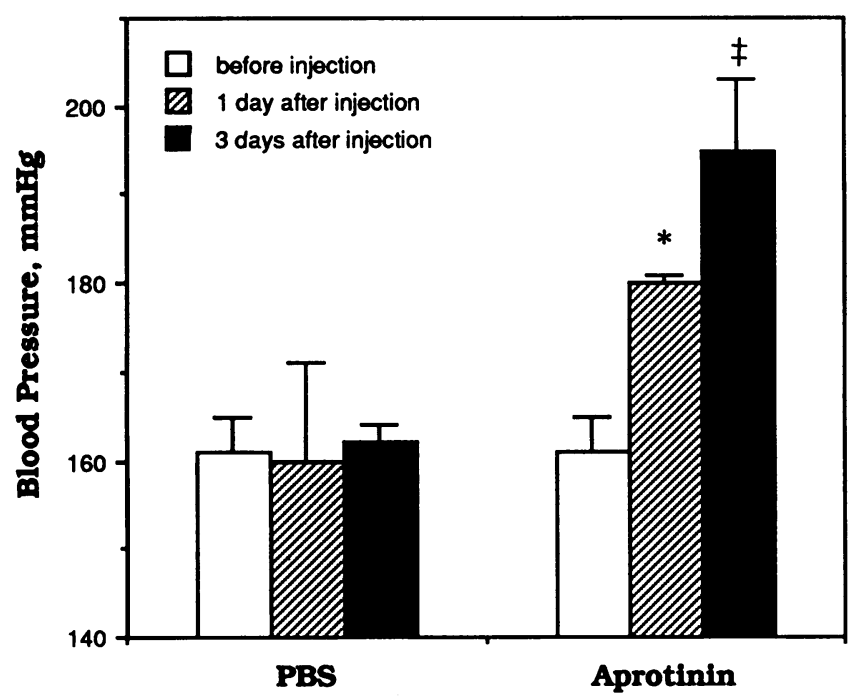

Figure 5. Effect of aprotinin on systolic blood pressure in SHR receiving intravenous injection of MRE-pHK plasmid DNA. Bars represent standard deviation. ${ }^{*} P<0.05$ between aprotinin vs PBS-treated groups at $1 \mathrm{~d}$ after injection $(n=3)$. $\ddagger P<0.01$ between aprotinin vs PBStreated groups at $3 \mathrm{~d}$ after injection $(n=3)$.

and two kallikrein DNA constructs, RSV-cHK and MRE-pHK, reached a maximum of 32 and $46 \mathrm{mmHg}$, respectively at $2 \mathrm{wk}$ after intravenous injection. Compared with the vector plasmid DNA, both human tissue kallikrein DNA constructs, RSV-cHK and MRE-pHK significantly decreased systolic blood pressure $(P<0.05)$ from 1 to $6 \mathrm{wk}$ after injection. At $7 \mathrm{wk}$ after injection, there was no significant difference in systolic blood pressure of SHR receiving injections of pREP8 ( $181 \pm 2 \mathrm{mmHg}$, $n=6)$ and RSV-cHK (176 $\pm 8 \mathrm{mmHg}, n=6)$, or MRE-pHK $(174 \pm 9 \mathrm{mmHg}, n=6)$ plasmid DNA. No apparent changes in body weight or reactivity were observed in SHR after delivery of the human tissue kallikrein gene.

Effect of aprotinin on blood pressure of SHR after gene delivery. Previous studies showed that a single subcutaneous injection of aprotinin, a potent tissue kallikrein inhibitor, resulted in the accumulation of aprotinin in renal proximal tubule cells of rats for at least $3 \mathrm{~d}$ (32). Fig. 5 depicts the blood pressure response to exogenous aprotinin observed 1 and $3 \mathrm{~d}$ after administration of aprotinin or PBS in SHR treated with MRE-pHK plasmid DNA for $6 \mathrm{wk}$. The decrease in systolic blood pressure caused by plasmid DNA MRE-pHK was markedly attenuated in SHR given aprotinin, when compared with PBS-treated animals. Increases in blood pressures of SHR with aprotinin administration were significantly higher at 1 and $3 \mathrm{~d}$ $(P<0.05$ and $P<0.01)$ after injection, whereas no significant changes of systolic blood pressure in SHR treated with PBS were observed at 1 and $3 \mathrm{~d}$ after injection. These results suggest that the enzymatic activity of human tissue kallikrein is crucial in the hypotensive effect caused by human tissue kallikrein gene delivery.

\section{Discussion}

This study shows that direct gene transfer of the naked human tissue kallikrein gene into SHR resulted in a sustained decrease in the systolic blood pressure of these animals. This hypotensive effect lasted $\sim 6 \mathrm{wk}$ after a single injection and expression of human tissue kallikrein was detected in the heart, kidney, and lung by ELISA and RT-PCR Southern blot analysis. These results raise the possibility of using kallikrein gene therapy for the treatment of human hypertensive diseases.

In recent years, evidence has been gathered to support the existence of a vascular kallikrein-kinin system in the rat and human. A kininogenase resembling glandular kallikrein is present in rat arteries and veins (33). Local synthesis of kallikrein is supported by the presence of specific kallikrein messenger RNA in rat vasculature (34). The arterial vasodilating action of kinins is mediated by the release of endothelium-derived relaxing factors and prostacyclin from endothelial cells. Kininogenase activity in thoracic aorta of SHR was lower than in agematched Wistar-Kyoto rats (35). It was hypothesized that the defective kinin release may contribute to increased blood pressure in SHR (35). An increased level of kinin generated by exogenous tissue kallikrein locally or in the circulation could be an alternative way to regulate blood pressure. In human arterial and venous vessels, a glandular kallikrein-like enzyme is present in both active and latent forms (36). Total amidolytic activity toward a peptidyl chromogenic substrate, Val-Leu-Arg$p$-nitroanilide, was found in saphenous vein homogenates and the activity was inversely correlated with mean blood pressure (37). In this study, exogenous human tissue kallikrein was detected in the heart of SHR suggesting that heart and arteries and veins are the primary targets that mediate the physiological function of exogenous kallikrein, which ultimately leads to a decrease in blood pressure.

It has been reported that intravenous injection of bradykinin or kallikrein causes a brief fall in blood pressure (38). Oral administration of pig pancreatic kallikrein has been shown to cause a temporary lowering of blood pressure in hypertensive patients $(16,17)$. Recently, oral kallikrein therapy on salt-sensitive essential hypertensive patients has been reported (39). These studies indicate that administration of exogenous tissue kallikrein can have an effect on blood pressure regulation. This is consistent with our finding that expression of the human tissue kallikrein gene in hypertensive rats causes a reduction of blood pressure by somatic gene delivery. We showed that human tissue kallikrein cleaves rat low $M_{\mathrm{r}}$ kininogen and releases kinin peptides, suggesting that the action of human tissue kallikrein is mediated by kinins generated from endogenous kininogen in rats. This hypothesis is supported by the fact that aprotinin, the tissue kallikrein inhibitor, can reverse the hypotensive effect of human tissue kallikrein in SHR. Based on the enzymatic activities of human tissue kallikrein on rat high and low $M_{\mathrm{r}}$ kininogens, we speculate that human tissue kallikrein cleaves rat low molecular weight kininogen to release bradykinin since both rat low and high $M_{\mathrm{r}}$ kininogens contain only bradykinin but not lysyl-bradykinin sequence (40).

Our present studies show that a single injection of the human tissue kallikrein gene results in expression of its encoded kallikrein and causes a reduction of blood pressure in SHR up to 6 wk. Prolonged expression of unprotected DNA was first demonstrated in mice after intramuscular injection (41). Gene delivery by intravenous injection has been demonstrated with the reporter gene construct. A single intravenous injection of the CAT expression plasmid complexed with cationic liposome into adult mice produced generalized CAT gene expression for at least 9 wk. High levels of CAT activity were present in the lung, spleen, liver, heart, kidney, and lymph nodes (42). We demonstrated 
that somatic gene delivery by intravenous injection of unprotected human tissue kallikrein plasmid DNA results in low, but generalized expression of human tissue kallikrein in heart, kidney, and lung and induces a significant reduction of blood pressure in the hypertensive rat model.

Previous studies showed that blood pressures of normotensive rats were not changed after either acute or chronic administration of aprotinin $(43,44)$. At $3 \mathrm{~d}$ after subcutaneous injection of aprotinin, renal and urinary kallikrein-like activities were markedly reduced (44). In addition, it has also been shown that a single subcutaneous injection of aprotinin, a potent tissue kallikrein inhibitor, resulted in accumulation of aprotinin in renal proximal tubule cells of rats for at least $3 \mathrm{~d}(32)$. We used the same gene delivery protocol as described in Methods to normotensive Sprague Dawley rats and found that the blood pressures were not affected up to 4 wk except for a slight blood pressure increase at $1 \mathrm{wk}$ after injection (data not shown). The initial increase of blood pressure observed in Sprague Dawley rats was similar to that observed in SHR. We have repeated the experiments a number of times and often observed this phenomenon. We speculate that the injection procedure induces a psychological stress which causes a transient increase of blood pressure in rats receiving either vector DNA or DNA constructs harboring the human tissue kallikrein gene. To alleviate the possibility of any blood pressure increase caused by the gene delivery procedure, alternative delivery methods will be pursued.

The development of efficient gene transfer methods in hypertensive animal models is essential to establishing practical therapeutic regimens in treating hypertensive diseases. Although viral vectors that have high levels of expression have been used for in vitro gene transfer experiments and human trials (45), their potential hazard is a concern since viral vectors used for gene delivery may have an opportunity for chromosomal insertion and therefore cause chromosomal breakage or carcinogenesis. Direct gene delivery by naked DNA, liposome, and receptor-mediated endocytosis have demonstrated expression of foreign products, and these methods may avoid potential hazards of using recombinant viruses in patients. By comparing different delivery methods in hypertensive animal models, it is possible to identify the best means of direct delivery of the human tissue kallikrein gene with combined advantages of high efficiency and safety.

Hypertension is the leading cause of both morbidity and mortality in the United States. Conventional therapy requires daily drug intake to control high blood pressure. The major advantage of applying kallikrein gene therapy is that a single injection of a gene construct has a long-lasting effect for months without apparent side effects. A potential problem with this technology may be the development of an immune response to the gene product after repeated injections. We found that the animals did not develop antibodies to either human tissue kallikrein or kallikrein DNA up to $7 \mathrm{wk}$ after injection of the gene construct. In addition, rats receiving kallikrein gene delivery did not experience any weight loss or changes in activity. Therefore, somatic gene therapy using human tissue kallikrein constructs offers a noninvasive, and a potentially important clinical alternative for treating human hypertensive diseases.

\section{Acknowledgments}

We thank Gary P. Richards and Dr. Carmelann Zintz for critical review of the manuscript.
This work was supported by the National Institutes of Health grant HL-29397.

\section{References}

1. Clements, J. A. 1989. The glandular kallikrein family of enzymes: tissuespecific expression and hormonal regulation. Endocr. Rev. 10:393-419.

2. Bhoola, K. D., C. D. Figueroa, and K. Worthy. 1992. Bioregulation of kinins: kallikreins, kininogens, and kininases. Pharmacol. Rev. 44:1-8.

3. Margolius, H. S. 1989. Tissue kallikreins and kinins: regulation and roles in hypertensive and diabetic diseases. Annu. Rev. Pharmacol. Toxicol. 29:343364.

4. Scicli, A. G., and O. A. Carretero. 1986. Renal kallikrein-kinin system. Kidney Int. 29:120-130.

5. Elliot, R., and F. R. Nuzum. 1934. The urinary excretion of a depressor substance (kallikrein of Frey and Kraut) in arterial hypertension. Endocrinology. 18:462-474.

6. Margolius, H. S., R. Geller, W. de Jong, J. J. Pisano, and A. Sjoerdsma. 1971. Altered urinary kallikrein excretion in human hypertension. Lancet. ii:10631065.

7. Zinner, S. H., H. S. Margolius, B. Rosner, and E. H. Kass. 1978. Stability of blood pressure rank and urinary kallikrein concentration in childhood: an eight year follow-up. Circulation. 58:908-915.

8. Margolius, H. S., D. Horwitz, J. J. Pisano, and H. R. Keiser. 1974. Urinary kallikrein excretion in hypertensive man. Relationships to sodium intake and sodium-retaining steroids. Circ. Res. 35:820-825.

9. Berry, T. D., S. J. Hasstedt, S. C. Hunt, L. L. Wu, J. B. Smith, K. O. Ash, H. Kuida, and R. R. Williams. 1989. A gene for high urinary kallikrein may protect against hypertension in Utah kindreds. Hypertension (Dallas). 13:3-8.

10. Ader, J. L., D. M. Pollock, M. I. Butterfield, and W. J. Arendshorst. 1985. Abnormalities in kallikrein excretion in spontaneously hypertensive rats. Am. J. Physiol. 248:F396-F403.

11. Favaro, S., B. Baggio, A. Antonello, A. Zen, G. Cannella, S. Todesco, and A. Borsatti. 1975. Renal kallikrein content of spontaneously hypertensive rats. Clin. Sci. Mol. Med. 49:69-71.

12. Margolius, H. S., R. Geller, W. De Jong, J. J. Pisano, and A. Sjoerdsma. 1972. Altered urinary kallikrein excretion in rats with hypertension. Circ. Res. 30:358-362.

13. Geller, R. G., H. S. Margolius, J. J. Pisano, and H. R. Keiser. 1975. Urinary kallikrein excretion in spontaneously hypertensive rats. Circ. Res. 36(Suppl. 1):103-106.

14. Woodley-Miller, C., J. Chao, and L. Chao. 1989. Restriction fragment length polymorphisms mapped in spontaneously hypertensive rats using kallikrein probes. J. Hypertens. 7:865-871.

15. Pravenec, M., V. Ken, J. Kunes, G. Scicli, O. A. Carretero, L. Simonet, and T. W. Kurtz. 1991. Cosegregation of blood pressure with a kallikrein gene family polymorphism. Hypertension (Dallas). 17:242-246.

16. Overlack, A., K. O. Stumpe, R. Kolloch, C. Ressel, and F. Krueck. 1981. Antihypertensive effect of orally administered glandular kallikrein in essential hypertension. Results of double blind study. Hypertension (Dallas). 3:I18-I21.

17. Ogawa, K., T. Ito, M. Ban, M. Mochizuki, and T. Satake. 1985. Effects of orally administered glandular kallikrein on urinary kallikrein and prostaglandin excretion, plasma immunoreactive prostanoids and platelet aggregation in essential hypertension. Klin. Wochenschr. 63:332-336.

18. Wang, J., W. Xiong, Z. Yang, T. Davis, M. J. Dewey, J. Chao, and L. Chao. 1994. Human tissue kallikrein induces hypotension in transgenic mice. Hypertension (Dallas). 23:236-243.

19. Fukushima, D., N. Kitamura, and S. Nakanishi. 1985. Nucleotide sequence of cloned cDNA for human pancreatic kallikrein. Biochemistry. 24:8037-8043.

20. Kozak, M. 1986. Point mutations define a sequence flanking the AUG initiator codon that modulate translation by eukaryotic ribosomes. Cell. 44:283292.

21. Glanville, N., D. M. Durnam, and R. D. Palmiter. 1981. Structure of mouse metallothionein-1 gene and its mRNA. Nature (Lond.). 292:267-269.

22. Sambrook, J., E. F. Fritsch, and T. Maniatis. 1989. Molecular Cloning: A Laboratory Manual. Cold Spring Harbor Laboratory Press, Cold Spring Harbor, NY. 16.33-16.36.

23. Shimamoto, K., J. Chao, and H. S. Margolius. 1982. A method for determination of human urinary inactive kallikrein (prekallikrein). Tohoku J. Exp. Med. 137:269-274.

24. Shimamoto, K., J. Chao, and H. S. Margolius. 1980. The radioimmunoassay of human tissue kallikrein and comparisons with kallikrein activity measurements. J. Clin. Endocrinol. \& Metab. 51:840-848.

25. Johnson, R. A., G. Salvesen, M. A. Brown, and A. J. Barrett. 1987. Rapid isolation of human kininogens. Thromb. Res. 48:187-193.

26. Shimamoto, K., S. Tonaka, T. Nakao, T. Ando, Y. Nakahashi, M. Sakuma, and M. Miyahara. 1979. Measurement of urinary kallikrein activity by kinin radioimmunoassay. Jpn. Circ. J. 43:147-152. 
27. Lowry, O. H., N. J. Rosebrough, A. L. Farr, and R. J. Randall. 1951. Protein measurement with the Folin phenol reagent. J. Biol. Chem. 193:265-275.

28. Chao, J., L. Chao, D. M. Tillman, C. M. Woodley, and H. S. Margolius. 1985. Characterization of monoclonal and polyclonal antibodies to human tissue kallikrein. Hypertension (Dallas). 7:931-937.

29. Guesdon, J. L., T. Ternynck, and S. Avrameas. 1979. The use of avidinbiotin interaction in immunoenzymatic techniques. J. Histochem. Cytochem. 27:1131-1139.

30. Gilkeson, G. S., D. D. Bloom, D. S. Pisetsky, and S. H. Clarke. 1993. Molecular characterization of anti-DNA antibodies induced in normal mice by immunization with bacterial DNA. Differences from spontaneous anti-DNA in the content and location of VH CDR3 arginines. J. Immunol. 15:1353-1364.

31. Sambrook, J., E. F. Fritsch, and T. Maniatis. 1989. Molecular Cloning: A Laboratory Manual. Cold Spring Harbor Laboratory Press, Cold Spring Harbor, NY. 7.19-7.22 pp.

32. Oestreicher, E., V. Velarde, A. Nalli, and C. P. Vio. 1993. Subcellular Distribution of Aprotinin in the Rat Nephron. Kinin 93 Brazil: 106.

33. Nolly, H., L. A. Carbini, G. Scicli, O. A. Carretero, and A. G. Scicli. 1994. A local kallikrein-kinin system is present in rat hearts. Hypertension (Dallas). 23:919-923.

34. Saed, G. M., O. A. Carretero, R. J. MacDonald, and A. G. Scicli. 1990 Kallikrein messenger RNA in rat arteries and veins. Circ. Res. 67:510-516.

35. Oza, N. B., and H. D. Goud. 1992. Kininogenase of the aortic wall in spontaneously hypertensive rats. J. Cardiovasc. Pharmacol. 20(Suppl. 9):1s-3s. 36. Madeddu, P., T. Gheli, P. P. Bacciu, M. Maioli, and N. Glorioso. 1993

A kallikrein-like enzyme in human vascular tissue. Am. J. Hypertens. 6:344-348.

37. Nolly, H., A. G. Scicli, G. Scicli, and D. A. Carretero. 1985. Characteriza- tion of a kininogenase from rat vascular tissue resembling tissue kallikrein. Circ. Res. 56:816-821.

38. Griesbacher, T., and F. Lembeck. 1992. Effects of the bradykinin antagonist, HOE 140, in experimental acute pancreatitis. Br. J. Pharmacol. 107:356360

39. Bellini, C., C. Ferri, A. Piccoli, A. Corlomagno, L. Di Francesco, M. S Bonavita, A. Santucci, and F. Balsano. 1993. The influence of salt-sensitivity on the blood pressure response to exogenous kallikrein in essential hypertensive patients. Nephron. 65:28-35.

40. Furuto-Kato, S., A. Matsumoto, N. Kitamura, and S. Nakanishi. 1985 Primary structure of the mRNAs encoding the rat precursors for bradykinin and T-kinin. J. Biol. Chem. 260:12054-12059.

41. Wolff, J. A., R. W. Malone, P. Williams, W. Chong, G. Acsadi, A. Jani, and P. L. Felgner. 1990. Direct gene transfer into mouse muscle in vivo. Science (Wash. DC). 247:1465-1468.

42. Zhu, N., D. Liggitt, Y. Liu, and R. Debs. 1993. Systemic gene expression after intravenous DNA delivery into adult mice. Science (Wash. DC). 261:209211

43. Jaffa, A. A., C. P. Vio, R. H. Silva, R. J. Vavrek, J. M. Stewart, P. F. Rust, and R. K. Mayfield. 1992. Evidence for renal kinins as mediators of amino acid-induced hyperperfusion and hyperfiltration in the rat. J. Clin. Invest. 89:1460-1468.

44. Jaffa, A. A., J. N. Harvey, S. E. Sutherland, H. S. Margolius, and R. K. Mayfield. 1989. Renal kallikrein responses to dietary protein: a possible mediator of hyperfiltration. Kidney Int. 36:1003-1010.

45. Flotte, T. R. 1993. Prospects for virus-based gene therapy for cystic fibrosis. J. Bioenerg. Biomembr. 25:37-42. 